\title{
Harmonized D-dimer levels upon admission for prognosis of COVID-19 severity: Results from a Spanish multicenter registry (BIOCOVID-Spain study)
}

\author{
Luis García de Guadiana-Romualdo' • Daniel Morell-García ${ }^{2}$ Emmanuel J. Favaloro ${ }^{3}$. Juan A. Vílchez ${ }^{4}$. \\ Josep M. Bauça ${ }^{2}$ - María J. Alcaide Martín ${ }^{5}$. Irene Gutiérrez Garcia ${ }^{6}$ · Patricia de la Hera Cagigal ${ }^{7}$. \\ José Manuel Egea-Caparrós ${ }^{8}$. Sonia Pérez Sanmartín ${ }^{9}$. José I. Gutiérrez Revilla ${ }^{10}$. Eloísa Urrechaga ${ }^{11}$. \\ Jose M. Álamo ${ }^{12}$. Ana M. Hernando Holgado ${ }^{13}$. María-Carmen Lorenzo-Lozano ${ }^{14}$. Magdalena Canalda Campás ${ }^{15}$. \\ María A. Juncos Tobarra ${ }^{16}$. Cristian Morales-Indiano ${ }^{17}$. Isabel Vírseda Chamorro ${ }^{18}$. Yolanda Pastor Murcia ${ }^{19}$. \\ Laura Sahuquillo Frías ${ }^{20}$. Laura Altimira Queral ${ }^{21}$. Elisa Nuez-Zaragoza ${ }^{22}$. Juan Adell Ruiz de León ${ }^{23}$. \\ Alicia Ruiz Ripa ${ }^{24}$. Paloma Salas Gómez-Pablos ${ }^{25}$ - Iria Cebreiros López ${ }^{26}$. Amaia Fernández Uriarte ${ }^{27}$. \\ Alex Larruzea ${ }^{28}$. María L. López Yepes ${ }^{29}$. Natalia Sancho-Rodríguez ${ }^{30}$. María C. Zamorano Andrés ${ }^{31}$. \\ José Pedregosa Díaz ${ }^{32}$ - Luis Sáenz ${ }^{33}$. Clara Esparza del Valle ${ }^{9}$ María C. Baamonde Calzada ${ }^{10}$ - Sara García Muñoz ${ }^{7}$ \\ Marina Vera ${ }^{12}$. Esther Martín Torres ${ }^{14}$. Silvia Sánchez Fdez-Pacheco ${ }^{15}$. Luis Vicente Gutiérrez ${ }^{16}$. \\ Laura Jiménez Añón ${ }^{17}$. Alfonso Pérez Martínez ${ }^{4}$. Aurelio Pons Castillo ${ }^{18}$. Ruth González Tamayo ${ }^{6}$. \\ Jorge Férriz Vivancos ${ }^{19}$. Olaia Rodríguez-Fraga ${ }^{5}$. Vicens Díaz-Brito ${ }^{34}$. Vicente Aguadero ${ }^{22} \cdot$ M. G. García Arévalo ${ }^{23}$. \\ María Arnaldos Carrillo ${ }^{26}$. Mercedes González Morales ${ }^{1}$. María Núñez Gárate ${ }^{27}$. Cristina Ruiz Iruela ${ }^{28}$. \\ Patricia Esteban Torrella ${ }^{30}$ - Martí Vila Pérez ${ }^{32}$. Cristina Acevedo Alcaraz ${ }^{8}$. Alfonso L. Blázquez-Manzanera ${ }^{33}$. \\ Amparo Galán Ortega ${ }^{35}$
}

Accepted: 4 July 2021 / Published online: 16 July 2021

(c) The Author(s), under exclusive licence to Springer Science+Business Media, LLC, part of Springer Nature 2021

\begin{abstract}
Coagulopathy is a key feature of COVID-19 and D-dimer has been reported as a predictor of severity. However, because D-dimer test results vary considerably among assays, resolving harmonization issues is fundamental to translate findings into clinical practice. In this retrospective multicenter study (BIOCOVID study), we aimed to analyze the value of harmonized D-dimer levels upon admission for the prediction of in-hospital mortality in COVID-19 patients. All-cause in-hospital mortality was defined as endpoint. For harmonization of D-dimer levels, we designed a model based on the transformation of method-specific regression lines to a reference regression line. The ability of D-dimer for prediction of death was explored by receiver operating characteristic curves analysis and the association with the endpoint by Cox regression analysis. Study population included 2663 patients. In-hospital mortality rate was $14.3 \%$. Harmonized D-dimer upon admission yielded an area under the curve of 0.66, with an optimal cut-off value of $0.945 \mathrm{mg} / \mathrm{L}$ FEU. Patients with harmonized D-dimer $\geq 0.945 \mathrm{mg} / \mathrm{L}$ FEU had a higher mortality rate $(22.4 \%$ vs. $9.2 \%$; $<0.001)$. D-dimer was an independent predictor of in-hospital mortality, with an adjusted hazard ratio of 1.709 . This is the first study in which a harmonization approach was performed to assure comparability of D-dimer levels measured by different assays. Elevated D-dimer levels upon admission were associated with a greater risk of in-hospital mortality among COVID-19 patients, but had limited performance as prognostic test.
\end{abstract}

Keywords COVID-19 $\cdot$ D-dimer $\cdot$ Harmonization $\cdot$ Prognosis $\cdot$ Mortality

Luis García de Guadiana-Romualdo and Daniel Morell-García contributed equally to this study.

Luis García de Guadiana-Romualdo

guadianarom@yahoo.es

Extended author information available on the last page of the article

\section{Introduction}

Coronavirus disease (COVID-19), which results from infection with the RNA virus SARS-CoV-2, was identified in late 2019 in China and characterized as a pandemic from March 2020. The role of clinical laboratories in this viral outbreak 
includes staging, prognosis and therapeutic monitoring of individuals with COVID-19 [1]. Several biomarkers have been reported to identify infected patients at higher risk of progression to severe disease [2]. From the onset of the pandemic, D-dimer was identified as one of the predictors of severity in COVID-19 patients [3].

Coagulopathy is a key finding of SARS-CoV-2 infection and is correlated with a poor prognosis [4]. Coagulopathy most commonly manifests as a pro-thrombotic state with increased incidence of both venous and arterial thrombosis [5]. Elevated D-dimer levels have consistently been shown as an important feature of severe COVID-19 patients [6-11]. Therefore, the International Society on Thrombosis and Haemostasis (ISTH) has recommended measuring D-dimer upon admission in all patients who present with COVID-19 [12]. However, several authors and scientific societies have highlighted significant problems across the medical literature with D-dimer reporting, creating confusion and potentially misleading data interpretation [13-15], as much of the published research does not include information on the analytical methods used for D-dimer testing [16]. In addition to the limited information on whether D-dimer units (DDU) or fibrinogen equivalent units (FEU) were used, and the inconsistencies in the magnitude of units reported, the main limitation of studies on the prognostic role of D-dimer in COVID-19 is that most failed to identify the manufacturer or type of D-dimer assay [14]. High inter-method variation is accepted as a major drawback of D-dimer assays, mainly caused by the heterogeneity of fibrin degradation products in patient samples, as well as the variable specificity of the different antibodies used in these assays [17]. This represents a potential source of bias, whereby standardization of D-dimer measurement is a key aspect in test result interpretation [14]. Besides, according to Lippi et al. [18], the adoption of the cut-off values reported in some studies for D-dimer in COVID-19 patients is unfeasible and unadvisable, due to the multiple analytical techniques that are currently available for the measurement of this biomarker. The complexity of target analyte and the variability among D-dimer assays specificity hamper assay standardization. Therefore, harmonization has been proposed to improve the comparability of results obtained with different assays [14], which could be achieved by conversion of $\mathrm{D}$-dimer values from different assays to a common scale, by applying a validated conversion factor $[16,17]$.

BIOCOVID-Spain study is an initiative by Laboratory Medicine professionals in Spain to generate a multicenter cohort database focusing on laboratory tests, including D-dimer. In this line, we aimed to evaluate the prognostic value of D-dimer levels in hospitalized COVID-19 patients, measured upon admission to the Emergency Department (ED), in hospitalized COVID-19 patients. Given the multicenter design of this study, and the use of four different
FDA-approved immunoturbidimetric assays for D-dimer, results were converted into a harmonized value to ensure comparability.

\section{Methods}

\section{Study setting}

BIOCOVID-Spain study is a multicenter, retrospective observational study including hospitalized patients with a diagnosis of COVID-19, recruited in 32 hospitals of the National Health System in 9 autonomous communities of Spain. The recruitment period for the current study was from March 1st, 2020, to April 30th, 2020. The follow-up censoring date was May 20th, 2020. The study was approved by the Ethics Committee of all participating hospitals. Because of the retrospective design, we received the approval for data collection with waiver of informed consent.

This study was endorsed by Spanish Association of Medical Biopathology and Laboratory Medicine (AEBM-ML), Spanish Association of Clinical Laboratory (AEFA) and Spanish Society of Laboratory Medicine (SEQC-ML).

\section{Patient eligibility}

All consecutive adult patients ( $\geq 14$ years) discharged or dead after hospital admission, with SARS-CoV-2 infection, were eligible for inclusion in the study, as previously described [19]. COVID-19 was diagnosed by a positive result of real-time reverse transcriptase-polymerase chain reaction (RT-PCR) testing of a nasopharyngeal specimen or by a positive result of serological testing and a clinically compatible presentation.

Exclusion criteria were: (a) patients $<14$ years; (b) pregnant women; (c) patients transferred from or to another hospital; (d) patients transferred from nursing homes; (e) patients discharged from the ED for at home treatment; (f) patients with Intensive Care Unit (ICU) admission criteria who were not admitted due to lack of availability; and (g) patients in whom D-dimer levels were not measured on admission to ED.

\section{Data collection}

Data collection was performed retrospectively from electronic medical records and laboratory information systems by two researchers for each hospital. For eligible patients, we extracted the demographics (age and gender), preexisting comorbidities (hypertension, chronic kidney disease (CKD), chronic obstructive pulmonary disease (COPD), cardiovascular disease (CVD) and diabetes mellitus) and laboratory tests. For measurement of D-dimer levels, four 
Table 1 Assays for measurement of D-dimer in BIOCOVID study

\begin{tabular}{llll}
\hline Assay & Units $^{\mathrm{a}}$ & Cut-off value & $\mathrm{n}(\%)$ \\
\hline $\begin{array}{l}\text { Siemens Innovance } \mathbb{} \\
\quad \text { D-dimer }\end{array}$ & $\mathrm{mg} / \mathrm{L}$ FEU & $0.5 \mathrm{mg} / \mathrm{L}$ & $513(19.3)$ \\
Stago STA Liatest D-Di & $\mu \mathrm{g} / \mathrm{mL}$ FEU & $0.5 \mu \mathrm{g} / \mathrm{mL}$ & $211(7.9)$ \\
HemosIL D-Dimer HS & $\mathrm{ng} / \mathrm{mL}$ DDU & $230 \mathrm{ng} / \mathrm{mL}$ & $324(12.2)$ \\
HemosIL D-Dimer HS-500 & $\mathrm{ng} / \mathrm{mL}$ FEU & $500 \mathrm{ng} / \mathrm{mL}$ & $1615(60.6$ \\
\hline
\end{tabular}

${ }^{\mathrm{a}}$ In our study, D-dimer levels, expressed in conventional units $(\mathrm{ng} / \mathrm{mL}$ and $\mu \mathrm{g} / \mathrm{mL}$ ), were converted to SI units ( $\mathrm{mg} / \mathrm{L}$ ) and expressed as FEU units

Adapted from Favaloro et al. [13]

immunoturbidimetric assays were used (Table 1). The primary outcome of interest was all-cause in-hospital mortality.

\section{Harmonization}

For the harmonization of results, four citrate plasma pools were prepared with a range of D-dimer levels. Normal pooled plasma was prepared from blood samples collected from 10 individuals without known thrombotic events or prior antiplatelet or anticoagulant treatment. Blood from the cubital vein was collected into tubes containing sodium citrate as anticoagulant, thoroughly mixed and immediately centrifugated at $2000 \times g$ for $15 \mathrm{~min}$. As pathological pooled plasma, a set of three plasma pools with increasing concentration of D-dimer were prepared, collecting for each pool blood samples from 10 patients with recent known thromboembolic events. Pools were analyzed within two hours of collection using the ACL TOP 700 analyzer (Instrumentation Laboratory, US) and HemosIL D-Dimer HS assay. Results were converted to FEU units.

Plasma was immediately separated, aliquoted and frozen at $-20{ }^{\circ} \mathrm{C}$ to be transported to other participating laboratories using the other D-dimer assays included in BIOCOVID study (Table 1). These laboratories were blinded to D-dimer concentrations. The storage time of the pools was less than 1 week until analysis. After thawing, samples were analyzed in duplicate within two hours.

In this study, the strategy for harmonization was based on a mathematical transformation of regression lines through the assay-specific values of a set of plasma samples with different D-dimer levels to a reference regression line [17, 20, 21]. Because HemosIL D-Dimer HS-500 was the assay mostly used in the BIOCOVID study, this was taken as reference and four lines were generated for the values previously reported (Table 2). The harmonization model was based on a linear transformation of the majority method's harmonized reference line $\left(\mathrm{y}_{\mathrm{h}}=2.197 \mathrm{x}_{\mathrm{h}}-2.843\right)$ and calculating $\mathrm{x}_{\mathrm{h}}$ by means of the line obtained in each method different from the reference one as $x_{h}=\left[\left(y_{m}-b_{m}\right) / a_{m}\right]$, according to the method described by Meijer et al. [21].
Table 2 Assay specific mean D-dimer levels (mg/L FEU) in normal and pathological plasma pools and lines obtained

\begin{tabular}{lcccc}
\hline Assay $^{\mathrm{a}}$ & Pool 1 & Pool 2 & Pool 3 & Pool 4 \\
\hline $\begin{array}{l}\text { Siemens Innovance® D-dimer } \\
\left(\mathrm{y}_{\mathrm{m}}=2.966 \mathrm{x}_{\mathrm{m}}-3.980\right)\end{array}$ & 0.525 & 1.160 & 1.885 & 10.170 \\
$\begin{array}{l}\text { Stago STA Liatest D-Di } \\
\left(\mathrm{y}_{\mathrm{m}}=2.655 \mathrm{x}_{\mathrm{m}}-3.495\right)\end{array}$ & 0.460 & 1.120 & 1.960 & 9.030 \\
$\begin{array}{l}\text { HemosIL D-Dimer HS } \\
\left(\mathrm{y}_{\mathrm{m}}=1.964 \mathrm{x}_{\mathrm{m}}-2.525\right)\end{array}$ & 0.374 & 0.950 & 1.472 & 6.748 \\
$\begin{array}{l}\text { HemosIL D-Dimer HS-500 } \\
\left(\mathrm{y}_{\mathrm{h}}=2.197 \mathrm{x}_{\mathrm{h}}-2.843\right)\end{array}$ & 0.393 & 1.075 & 1.582 & 7.542 \\
\begin{tabular}{l} 
Overall mean value \\
\hline
\end{tabular} & 0.438 & 1.076 & 1.724 & 8.372 \\
\hline
\end{tabular}

${ }^{\text {a }}$ Slope and intercept expressed as $\mathrm{mg} / \mathrm{L}$

For the external validation of the harmonization model, results were collected from two levels of quality control for D-dimer included in the External Quality Assurance (EQA) scheme, provided by the Spanish Society of Hematology and Hemostasis (SEHH) in November 2020.

\section{Statistical analysis}

Continuous variables were tested for normal distribution using the Kolmogorov-Smirnov's test. Data are summarized as numbers and frequencies for categorical variables and medians with interquartile ranges (IQRs) for continuous data. Comparisons between groups were performed with Chi-squared test for categorical data and Mann-Whitney's $\mathrm{U}$ tests for continuous data. For harmonized D-dimer, optimal cut-off value for mortality was calculated by Youden's index from a Receiver Operating Characteristic (ROC) curve analysis. For the survival analysis, time zero was defined as the time of admission to the ED. In order to assess survival probability by the Kaplan-Meier's method and log rank test, with the end-point being all-cause in-hospital mortality, the study population was divided according to the optimal cutoff value for D-dimer. Cox proportional hazards regression was performed for both univariate and multivariate analyses. Regression analyses were adjusted for age, gender, hypertension, CVD, diabetes mellitus, CKD and COPD. Statistical significance was set at 5\%. SPSS software version 20 (IBM Corporation, USA) was used for all statistical analyses.

\section{Results}

\section{Harmonization}

Mean D-dimer concentrations $(\mathrm{mg} / \mathrm{L})$ in harmonization plasma pools for each assay were obtained. Slope and intercept of the linear regression analysis through the assay 
specific values are shown in Table 2. The highest D-dimer levels were observed with Siemens Innovance ${ }^{\circledR} \mathrm{D}$-dimer assay.

For external validation, a total of 32 results were included. The means for the first and second levels measured by the reference method (HemosIL D-dimer HS-500) were 0.945 and $0.930 \mathrm{mg} / \mathrm{L}$ FEU, respectively. Results from the other three methods were harmonized, resulting in 0.735 and $0.703 \mathrm{mg} / \mathrm{L}$ FEU (HemosIL D-Dimer HS, Werfen), 0.752 and $0.554 \mathrm{mg} / \mathrm{L}$ FEU (Stago STA Liatest D-Di) and 0.638 and $0.705 \mathrm{mg} / \mathrm{L}$ FEU (Siemens Innovance ${ }^{\circledR}$ D-dimer). A non-parametric linear correlation of the measured-harmonized values and harmonized-reference method values was performed, yielding a coefficient of $\mathrm{r}=0.846(\mathrm{p}<0.01)$, with a mean difference between values of $-21.2 \%$ (95\% CI -45.3 to $12.6 \%)$; these differences were non-significant $(p=0.09)$. A measure of quality control level 2 was excluded for the calculation of the adjusted Cohen's Kappa index, resulting in $\kappa=0.636$, with a degree of concordance of $94.4 \%$ for a total of 16 pairs of values.

According to Landis et al. [22], these data reveal substantial agreement, with a significant correlation between measured values and those harmonized according to the reference method.

\section{Characteristics of study subjects}

During the study period, a total of 2981 COVID-19 patients admitted to 32 Spanish hospitals were recruited. One-hundred and eight patients who were still hospitalized on May 20th, 2020, were excluded from analyses. D-dimer levels on admission were not available in 210 patients. Thus, the study population finally included 2663 hospitalized COVID19 patients (Fig. 1). Median age was 65 years (IQR 54-76), ranging from 15 to 98 years, and 1560 patients were male (58.6\%). The most common comorbidity was hypertension (45.3\%), followed by diabetes mellitus (23.8\%) and prior CVD (22.4\%).

In-hospital mortality rate was $14.3 \%$ (364/2663). Characteristics of the study population according to in-hospital mortality are summarized in Table 3. Median harmonized D-dimer in the study population was $0.690 \mathrm{mg} / \mathrm{L}$ FEU (IQR $0.438-1.200)$, and 1787 (67.1\%) presented with a level greater than $0.500 \mathrm{mg} / \mathrm{L} \mathrm{FEU}$, usually defined as the upper reference limit for identification of venous thromboembolic disease. Compared to survivors, non-survivors were older and commonly male and presented an increased prevalence of all the comorbidities; regarding laboratory tests, creatinine, lactate dehydrogenase (LDH), C-reactive protein (CRP) and D-dimer levels were higher and lymphocyte and platelet counts were lower in patients who died.

Harmonized D-dimer levels were significantly higher in patients who died (1.019 mg/L FEU [IQR 0.564-2.155] $v s$.

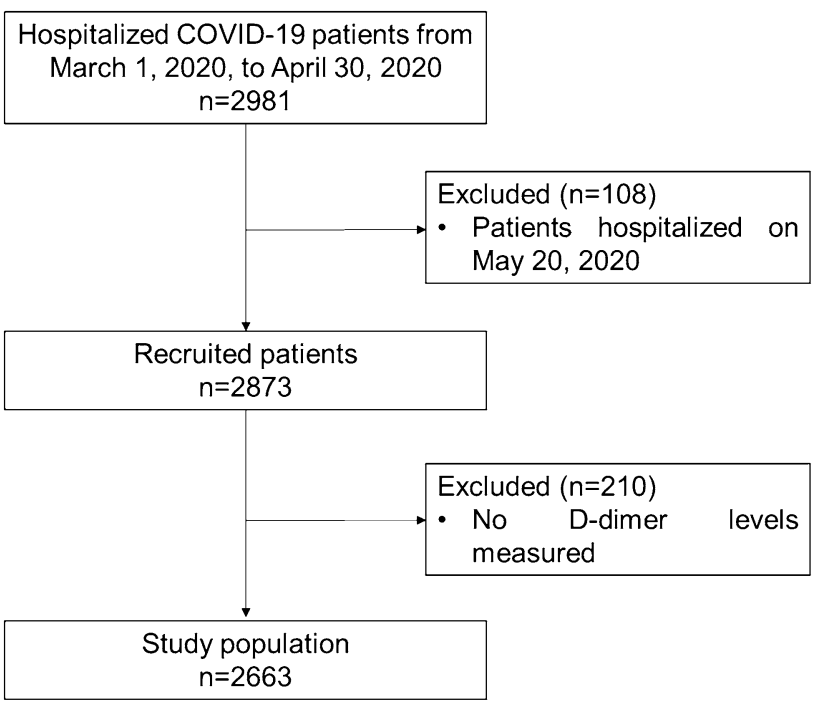

Fig. 1 Flowchart of patient recruitment

$0.645 \mathrm{mg} / \mathrm{L}$ FEU [IQR 0.422-1.108]; $\mathrm{p}<0.001$ ). AUC for baseline D-dimer levels as a predictor of death was 0.66 (95\% Confidence interval (CI) $0.63-0.69 ; \mathrm{p}<0.001$ ), consistent with relatively poor discriminating ability for prognosis of this endpoint. According to the Youden's index, the optimal cut-off value of harmonized D-dimer was $0.945 \mathrm{mg} / \mathrm{L}$ FEU (sensitivity: $55.8 \%$ (95\% CI 50.5-60.9\%); specificity: $69.3 \%$ (95\% CI $67.4-71.2 \%$ ); positive predictive value: $22.4 \%$ (95\% CI 19.7-25.2\%), negative predictive value: $90.8 \%$ (95\% CI 89.4-92.1). According to regression equations for harmonization, this cut-off value was equal to $0.862,1.083$ and $1.136 \mathrm{mg} / \mathrm{L}$ FEU for HemosIL D-Dimer HS, Stago STA Liatest D-Di and Siemens Innovance ${ }^{\circledR}$ D-dimer assays, respectively.

Patients with a harmonized D-dimer $\geq 0.945 \mathrm{mg} / \mathrm{L}$ FEU were older and comorbidities were more frequent, including hypertension, diabetes mellitus, COPD, CVD and CKD. In terms of laboratory tests, patients with a harmonized D-dimer $\geq 0.945 \mathrm{mg} / \mathrm{L}$ FEU had higher creatinine, CRP levels and platelet count along with a lower lymphocyte count (Table 4).

\section{Association of D-dimer and in-hospital mortality}

In-hospital mortality was higher among patients with a harmonized D-dimer level $\geq 0.945 \mathrm{mg} / \mathrm{L}$ FEU (203 [22.4\%] vs. 161 [9.2\%]; $\mathrm{p}<0.001)$. Kaplan-Meier's survival analysis was used to evaluate in-hospital mortality in COVID-19 patients with different D-dimer levels, according to optimal cut-off value. A significant association between D-dimer and mortality was observed (log-rank test $\mathrm{p}<0.001)$ (Fig. 2).

In multivariate Cox regression analysis, the hazard ratio (HR) for patients with D-dimer levels $\geq 0.945 \mathrm{mg} / \mathrm{L} \mathrm{FEU}$ 
Table 3 Patients' characteristics of patients in total population grouped by survival status

\begin{tabular}{|c|c|c|c|}
\hline $\begin{array}{l}\text { Variable } \\
\mathrm{n}(\%)\end{array}$ & $\begin{array}{l}\text { Survivors } \\
2299(86.3)\end{array}$ & $\begin{array}{l}\text { Non-survivors } \\
364 \text { (13.7) }\end{array}$ & $p$-value \\
\hline \multicolumn{4}{|l|}{ Demographics } \\
\hline Age (years) & $63(52-74)$ & $76(68-83)$ & $<0.001$ \\
\hline Gender (male) & $1317(57.3)$ & $243(66.8)$ & 0.001 \\
\hline \multicolumn{4}{|l|}{ Pre-existing comorbidities } \\
\hline Hypertension [n (\%)] & 963 (41.9) & $243(66.8)$ & $<0.001$ \\
\hline Diabetes mellitus [n (\%)] & $508(22.1)$ & $126(34.6)$ & $<0.001$ \\
\hline Cardiovascular disease $[\mathrm{n}(\%)]$ & $453(19.7)$ & $144(39.6)$ & $<0.001$ \\
\hline COPD $[\mathrm{n}(\%)]$ & $164(7.1)$ & $56(15.4)$ & $<0.001$ \\
\hline Chronic kidney injury [n (\%)] & $141(6.1)$ & $75(20.6)$ & $<0.001$ \\
\hline \multicolumn{4}{|l|}{ Laboratory findings } \\
\hline Harmonized D-dimer (mg/L FEU), $\mathrm{n}=2663$ & $0.645(0.422-1.108)$ & $1.019(0.564-2.155)$ & $<0.001$ \\
\hline $\mathrm{CRP}(\mathrm{mg} / \mathrm{L}), \mathrm{n}=2609$ & $68.3(30.2-135.6)$ & $136.4(76.8-205.7)$ & $<0.001$ \\
\hline Creatinine $(\mu \mathrm{mol} / \mathrm{L}), \mathrm{n}=2654$ & $76.9(63.7-94.6)$ & $101.7(78.7-138.8)$ & $<0.001$ \\
\hline Alanine aminotransferase (U/L), $\mathrm{n}=2542$ & $28(18-47)$ & $26(17-45)$ & 0.208 \\
\hline $\mathrm{LDH}(\mathrm{U} / \mathrm{L}), \mathrm{n}=2370$ & $295(232-387)$ & $394(292-557)$ & $<0.001$ \\
\hline Lymphocyte count $\left(* 10^{9} / \mathrm{L}\right), \mathrm{n}=2661$ & $1.00(0.70-1.39)$ & $0.80(0.53-1.10)$ & $<0.001$ \\
\hline Platelet count $\left(* 10^{9} / \mathrm{L}\right), \mathrm{n}=2661$ & $197(155-261)$ & $185(136-243)$ & $<0.001$ \\
\hline
\end{tabular}

$C O P D$ Chronic obstructive pulmonary disease, $L D H$ Lactate dehydrogenase, $C R P$ C-reactive protein

Table 4 Patients' characteristics according to harmonized D-dimer level on admission

\begin{tabular}{|c|c|c|c|c|}
\hline & \multirow{2}{*}{$\begin{array}{l}\text { Total population } \\
\mathrm{n}=2663\end{array}$} & \multicolumn{2}{|c|}{ Harmonized D-dimer level } & \multirow[t]{2}{*}{ p-value } \\
\hline & & $\begin{array}{l}<0.945 \mathrm{mg} / \mathrm{L} \text { FEU } \\
\mathrm{n}=1755(65.9 \%)\end{array}$ & $\begin{array}{l}\geq 0.945 \mathrm{mg} / \mathrm{L} \text { FEU } \\
\mathrm{n}=908(34.1 \%)\end{array}$ & \\
\hline Age, years [Median (IQR)] & $65(54-76)$ & $62(50-73)$ & $71(62-80)$ & $<0.001$ \\
\hline Gender, male $[\mathrm{n}(\%)]$ & $1560(58.6)$ & $1039(59.2)$ & $521(57.4)$ & 0.365 \\
\hline In-hospital mortality [n (\%)] & $364(13.7)$ & $161(9.2)$ & $203(22.4)$ & $<0.001$ \\
\hline \multicolumn{5}{|l|}{ Pre-existing comorbidities } \\
\hline Hypertension [n (\%)] & $1206(45.3)$ & 715 (40.7) & $491(54.1)$ & $<0.001$ \\
\hline Diabetes mellitus [n (\%)] & $634(23.8)$ & $370(21.1)$ & $264(29.1)$ & $<0.001$ \\
\hline COPD [n (\%)] & $220(8.3)$ & $125(7.1)$ & $95(10.5)$ & 0.003 \\
\hline Cardiovascular disease $[\mathrm{n}(\%)]$ & $597(22.4)$ & $353(20.1)$ & $244(26.9)$ & $<0.001$ \\
\hline Chronic kidney disease $[\mathrm{n}(\%)]$ & $216(8.1)$ & $111(6.3)$ & 105 (11.6) & $<0.001$ \\
\hline \multicolumn{5}{|c|}{ Laboratory tests on admission (Median [IQR]) } \\
\hline Creatinine $(\mu \mathrm{mol} / \mathrm{L})$ & $78.7(64.5-101.7)$ & $76.9(63.7-93.7)$ & $84.0(67.2-118.5)$ & $<0.001$ \\
\hline Alanine aminotransferase (U/L) & $28(18-46)$ & $28(18-46)$ & $28(17-47)$ & 0.602 \\
\hline $\mathrm{LDH}(\mathrm{U} / \mathrm{L})$ & $306(237-407)$ & $287(228-372)$ & $356(264-491)$ & $<0.001$ \\
\hline $\mathrm{CRP}(\mathrm{mg} / \mathrm{L})$ & $77(34-147)$ & $63(28-122)$ & $110(52-189)$ & $<0.001$ \\
\hline Lymphocyte count $\left(* 10^{9} / \mathrm{L}\right)$ & $1.00(0.70-1.35)$ & $1.00(0.70-1.39)$ & $0.92(0.61-1.30)$ & $<0.001$ \\
\hline Platelet count $\left(* 10^{9} / \mathrm{L}\right)$ & $196(152-256)$ & $190(152-242)$ & $209(157-286)$ & $<0.001$ \\
\hline Harmonized D-dimer (mg/L FEU) & $0.697(0.438-1.200)$ & - & - & - \\
\hline
\end{tabular}

COPD Chronic obstructive pulmonary disease, $L D H$ Lactate dehydrogenase, $C R P C$-reactive protein 


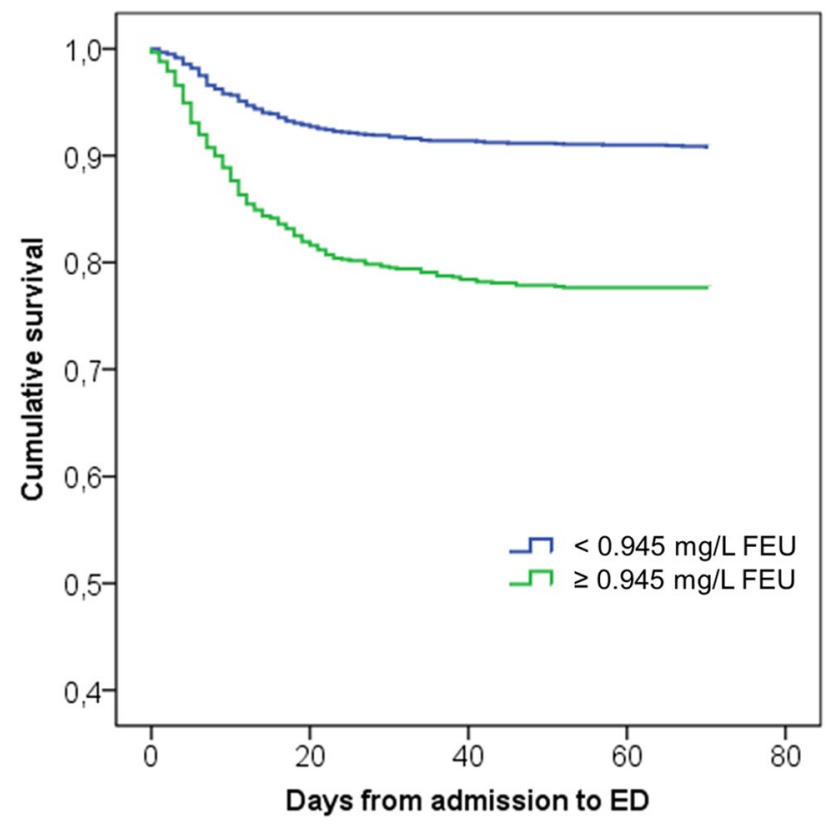

Fig. 2 Cumulative incidence of in-hospital mortality during hospitalization stratified by D-dimer on admission

remained significant after adjusting for age, gender, hypertension, diabetes, CVD, CKD and COPD (HR 1.709, 95\% CI 1.380-2.115; $\mathrm{p}<0.001$ ) (Table 5).

\section{Discussion}

In this multicenter study, we retrospectively analyzed the prognostic role of harmonized D-dimer in a large population including hospitalized COVID-19 in 32 Spanish hospitals, with clinical and demographic characteristics similar to those recently described in other COVID-19 Spanish cohorts [23, 24]. Our study shows that elevated D-dimer levels upon admission, previously harmonized to guarantee the comparability among different assays, were associated with a higher risk of in-hospital all-cause mortality. However, D-dimer levels upon admission, as an isolated measure, did not appear to be a reliable prognostic laboratory test for death among COVID-19 patients.

The potential prognostic role of D-dimer would be based in the fact that COVID-19 patients commonly experience a coagulopathy with different characteristics from those seen in bacterial sepsis-induced coagulopathy and disseminated intravascular coagulation; COVID-19 coagulopathy is also associated with a high incidence of thrombotic events leading to poor outcomes $[4,5,25,26]$. Hence, biomarkers of coagulation, such as D-dimer, may be helpful in predicting clinical course and outcomes in these patients and its measurement upon admission to hospital has been recommended to identify early those COVID-19 patients at high-risk of thromboembolic events [27] and a poor evolution [12, 28].

Although the molecular mechanisms underlying the hypercoagulable state described in COVID-19 patients are still incompletely understood (with endotheliopathy, due to the direct endothelial infection with SARS-CoV-2 and the indirect damage caused by inflammation, playing a predominant role) [29], multiple studies, reviews and meta-analyses have reported higher D-dimer levels to be associated with poorer outcomes and may even help predict these outcomes [6-11]. However, this potential role is controversial. Although D-dimer levels might be attractive for the management of COVID-19, Gris et al. [30] reported that the cutoff points are variable and the clinical interpretation is still very uncertain. Importantly, no differential treatment exists that elevated D-dimer levels alone can promote. Therefore, this biomarker cannot currently be used to improve either management or prognosis. Furthermore, its utility remains beset with uncertainties by a lack of information in studies about D-dimer assays and their characteristics [13], which prevents the adoption of the cut-off points recommended in these studies [28].

Similar to previous reports [31], in ours, D-dimer elevation upon admission was frequently observed in our study (67\%). This increase is one of the most consistent abnormal
Table 5 Cox regression model showing hazard ratios for the studied variables

\begin{tabular}{|c|c|c|c|c|}
\hline & \multicolumn{2}{|l|}{ Univariate analysis } & \multicolumn{2}{|l|}{ Multivariate analysis } \\
\hline & $\mathrm{HR}(95 \% \mathrm{CI})$ & $p$-value & HR $(95 \%$ CI $)$ & $p$-value \\
\hline Age & $1.064(1.055-1.073)$ & $<0.001$ & $1.055(1.045-1.065)$ & $<0.001$ \\
\hline Male sex & $1.454(1.169-1.808)$ & 0.001 & $1.762(1.412-2.199)$ & $<0.001$ \\
\hline Hypertension & $2.589(2.089-3.232)$ & $<0.001$ & $1.286(1.020-1.620)$ & 0.033 \\
\hline Diabetes mellitus & $1.773(1.429-2.201)$ & $<0.001$ & - & ns \\
\hline COPD & $2.155(1.621-2.865)$ & $<0.001$ & - & ns \\
\hline Cardiovascular disease & $2.473(2.004-3.051)$ & $<0.001$ & - & ns \\
\hline Chronic kidney disease & $3.357(2.604-4.329)$ & $<0.001$ & $1.822(1.401-2.370)$ & $<0.001$ \\
\hline D-dimer $\geq 0.945 \mathrm{mg} / \mathrm{L} \mathrm{FEU}$ & $2.636(2.143-3.232)$ & $<0.001$ & $1.709(1.380-2.115)$ & $<0.001$ \\
\hline
\end{tabular}

$H R$ Hazard ratio, $C I$ Confidence interval, COPD Chronic obstructive pulmonary disease, $n s$ non-significant 
hemostatic laboratory tests in COVID-19 [31] and has been described in patients without confirmed pulmonary embolism/deep vein thrombosis or laboratory evidence compatible with disseminated intravascular coagulopathy (DIC). This supports its role not just a diagnostic tool for thromboembolism or DIC. Recently, the association of lung inflammation caused by SARS-CoV-2 infection with elevated fibrinogen levels has been hypothesized [32,33]. Previous studies reported that early steps of viral invasion in the lung comprise airway inflammation and the leakage of various plasma proteins, including thrombin and fibrinogen [34]. Both proteins are leaked into the extravascular space and fibrinogen is converted into fibrin by thrombin and then degraded by the proteases released from neutrophils. In this line, high plasma fibrinogen levels and D-dimer are reported in patients with COVID-19 [35]. D-dimer formed in this manner may not imply generalised thrombus formation but could predict a poor prognosis, as they arise from lung exudates. Hunt et al. [36] have also recently suggested that the origin of elevated $\mathrm{D}$-dimer levels is a direct consequence of an acute lung injury seen in COVID-19 pneumonia; hence, similar to other acutephase proteins such as CRP, ferritin and fibrinogen, elevated D-dimer levels represent the degree of lung inflammation within the lungs in COVID-19. Moreover, being associated with the extent of this inflammation would explain why their plasma levels relate to clinical outcome.

Nevertheless, results from studies exploring the prognostic role of D-dimer are controversial. In addition, one of the main limitations in such literature is a lack of information about analytical methodologies used, which are known to be not interchangeable among them and require a previous harmonization, alongside with the different units for expression of D-dimer. These issues might lead to misinterpretations $[13,16]$, and hinder the translation of study findings into local laboratory practice [28].

D-dimer was one of the first biomarkers reported as useful for the prediction of a poor prognosis at an early stage in COVID-19 patients [3]. Subsequent studies confirmed the significant association of D-dimer levels with greater risk of all-cause mortality, with a wide variety of optimal cut-off values reported as predictors of death, including $1128 \mathrm{ng} /$ $\mathrm{mL}$ [37], $2.00 \mu \mathrm{g} / \mathrm{mL}$ [38], $2.14 \mathrm{mg} / \mathrm{L}$ [39] and $2.38 \mu \mathrm{g} / \mathrm{mL}$ [40], although an association was not detected by MartínRojas et al. [4]. In our study, a higher harmonized D-dimer $(\geq 0.945 \mathrm{mg} / \mathrm{L}$ FEU) on admission was also associated with greater risk of all-cause mortality. However, D-dimer, as an isolated measure evaluated by a ROC curve analysis, was not a reliable tool for predicting mortality among COVID-19 patients, showing a low AUC (0.66), similar to those recently reported by Chocron et al. [37] (0.65) and Naymagon et al. [40] (0.69), but significantly lower than reported by Yao et al. (0.85) [39] and Zhang et al. (0.89) [38]. According to Gris et al. [30], selection bias would be a major confounding factor affecting the results in Chinese populations, with mortality rates (3.8\% [38] and 6.9\% [39], respectively) being lower than those found in western cohorts (14.3\% in ours). These authors suggest that the patients enrolled in the study by Zhang et al. [38] were not initially affected by major severity criteria, likely by the non-representativeness of the patients analyzed by comparison with all the COVID-19 hospitalized into the recruiting medical centers, affecting the applicability of generalizing their results to all COVID-19 patients. Therefore, the value of using D-dimer for management of COVID-19 is strongly dependent on the true clinical representativeness and characteristics of the included patients [30].

\section{Strengths and limitations}

One of the main strengths of this work, in addition to the sample size, is the effort to harmonize D-dimer values, measured by different assays, to guarantee their comparability. To the best of our knowledge, no previous multicenter study has performed a similar approach.

Our study has some limitations. First, selection bias could have been introduced due to the retrospective design. Second, outcomes other than death, such as thrombosis, need of mechanical ventilation or critical illness were not included in this study [32]. Third, it should be noted that the differences between results of external validation were negative by more than $20 \%$ and the statistical significance below $10 \%$ suggests that they may become significant should the sample size be increased to enable a more extensive external validation. Fourth, in our study, only the prognostic role of D-dimer levels upon admission was explored; some studies have reported a high ability of D-dimer peak during hospital stay for prediction of multiple outcomes [41]. We also did not analyze the potential role of serial D-dimer levels to distinguish severe COVID-19 cases from the mild/moderate forms [42].

\section{Conclusion}

We performed a harmonization approach to ensure the comparability of D-dimer levels measured with different assays, and identified that higher D-dimer levels upon admission were associated with significantly greater risk of in-hospital mortality among hospitalized COVID-19 patients. Nevertheless, admission D-dimer had a limited usefulness as prognostic test.

Author contribution LGGR and DMG conceived, designed the study, supervised the conduct of the trial and analyzed the data. LGGR, DMG, EJF and JMB drafted the article. LGGR, DMG, IGG and PHC contributed to measure D-dimer levels for harmonization. All the authors contributed to data collection in the participating hospitals, contributed to its revision and gave approval before submission. 
Funding None.

\section{Declarations}

Conflicts of interest The authors state that there are no conflicts of interest to disclose.

Ethics approval The study was approved by the Ethics Committee of all participating hospitals. Because of the retrospective design, we received the approval for data collection with waiver of informed consent.

\section{References}

1. Lippi G, Plebani M (2020) The critical role of laboratory medicine during coronavirus disease 2019 (COVID-19) and other viral outbreaks. Clin Chem Lab Med 58:1063-1069. https://doi.org/10. 1515/cclm-2020-0240

2. Frater JL, Zini G, d'Onofrio G, Rogers HJ (2020) COVID-19 and the clinical hematology laboratory. Int J Lab Hematol 42(Suppl 1):11-18. https://doi.org/10.1111/ijlh.13229

3. Zhou F, Yu T, Du R, Fan G, Liu Y, Liu Z, Xiang J, Wang Y, Song B, Gu X, Guan L, Wei Y, Li H, Wu X, Xu J, Tu S, Zhang Y, Chen H, Cao B (2020) Clinical course and risk factors for mortality of adult inpatients with COVID-19 in Wuhan, China: a retrospective cohort study. Lancet 395:1054-1062. https://doi.org/10.1016/ S0140-6736(20)30566-3

4. Martín-Rojas RM, Pérez-Rus G, Delgado-Pinos VE, DomingoGonzález A, Regalado-Artamendi I, Alba-Urdiales N, DemeloRodríguez P, Monsalvo S, Rodríguez-Macías G, Ballesteros M, Osorio-Prendes S, Díez-Martín JL, Pascual Izquierdo C (2020) COVID-19 coagulopathy: an in-depth analysis of the coagulation system. Eur J Haematol 105:741-750. https://doi.org/10.1111/ejh. 13501

5. Becker RC (2020) COVID-19 update: Covid-19-associated coagulopathy. J Thromb Thrombolysis 50:54-67. https://doi.org/10. 1007/s11239-020-02134-3

6. Sakka M, Connors JM, Hékimian G, Martin-Toutain I, Crichi B, Colmegna I, Bonnefont-Rousselot D, Farge D, Frere C (2020) Association between D-Dimer levels and mortality in patients with coronavirus disease 2019 (COVID-19): a systematic review and pooled analysis. J Med Vasc 45:268-274. https://doi.org/10. 1016/j.jdmv.2020.05.003

7. Gungor B, Atici A, Baycan OF, Alici G, Ozturk F, Tugrul S, Asoglu R, Cevik E, Sahin I, Barman HA (2021) Elevated D-dimer levels on admission are associated with severity and increased risk of mortality in COVID-19: a systematic review and metaanalysis. Am J Emerg Med 39:173-179. https://doi.org/10.1016/j. ajem.2020.09.018

8. Lippi G, Favaloro EJ (2020) D-dimer is associated with severity of coronavirus disease 2019: a pooled analysis. Thromb Haemost 120:876-878. https://doi.org/10.1055/s-0040-1709650

9. Vidali S, Morosetti D, Cossu E, Luisi MLE, Pancani S, Semeraro V, Consales G (2020) D-dimer as an indicator of prognosis in SARS-CoV-2 infection: a systematic review. ERJ Open Res 6:00260-02020. https://doi.org/10.1183/23120541.00260-2020

10. Shi L, Wang Y, Wang Y, Duan G, Yang H (2020) An updated meta-analysis on the relationship between D-dimer levels and severity of coronavirus disease 2019. Int J Lab Hematol 42:e207e210. https://doi.org/10.1111/ijlh.13268

11. Nugroho J, Wardhana A, Maghfirah I, Mulia EPB, Rachmi DA, A'yun MQ, Septianda I (2020) Relationship of D-dimer with severity and mortality in SARS-CoV-2 patients: a meta-analysis. Int J Lab Hematol 43:110-115. https://doi.org/10.1111/ijlh.13336

12. Thachil J, Tang N, Gando S, Falanga A, Cattaneo M, Levi M, Clark C, Iba T (2020) ISTH interim guidance on recognition and management of coagulopathy in COVID-19. J Thromb Haemost 18:1023-1026. https://doi.org/10.1111/jth.14810

13. Favaloro EJ, Thachil J (2020) Reporting of D-dimer data in COVID-19: some confusion and potential for misinformation. Clin Chem Lab Med 58:1191-1199. https://doi.org/10.1515/ cclm-2020-0573

14. Thachil J, Longstaff C, Favaloro EJ, Lippi G, Urano T, Kim PY, SSC Subcommittee on Fibrinolysis of the International Society on Thrombosis and Haemostasis (2020) The need for accurate D-dimer reporting in COVID-19: communication from the ISTH SSC on fibrinolysis. J Thromb Haemost 18:2408-2411. https:// doi.org/10.1111/jth.14956

15. Favaloro EJ, Dean E (2020) Variability in D-dimer reporting revisited. Pathology. https://doi.org/10.1016/j.pathol.2020.08.010

16. Aloisio E, Serafini L, Chibireva M, Dolci A, Panteghini M (2020) Hypoalbuminemia and elevated D-dimer in COVID-19 patients: a call for result harmonization. Clin Chem Lab Med 58:e255-e256. https://doi.org/10.1515/cclm-2020-1038

17. Segnar M, Bozic M (2008) Determination of D-dimer by different quantitative assays-A harmonization exercise. Biochem Med $18: 216-223$

18. Lippi G, Favaloro EJ (2020) D-dimer measurement in COVID-19: Silver bullet or clinical distraction? Thromb Res 196:635-657. https://doi.org/10.1016/j.thromres.2020.09.040

19. García de Guadiana-Romualdo L, Morell-García D, MoralesIndiano C, Bauça JM, Alcaide Martín MJ, Esparza Del Valle C, Gutiérrez Revilla JI, Urrechaga E, Álamo JM, Hernando Holgado AM, Lorenzo-Lozano MC, Sánchez Fdez-Pacheco S, de la Hera CP, Juncos Tobarra MA, Vílchez JA, Vírseda Chamorro I, Gutiérrez Garcia I, Pastor Murcia Y, Sahuquillo Frías L, Altimira Queral L, Nuez-Zaragoza E, Ruiz A, de León J, Ruiz Ripa A, Salas Gómez-Pablos P, Cebreiros López I, Fernández Uriarte A, Larruzea Á, López Yepes ML, Esteban Torrella P, Zamorano Andrés MC, Pedregosa Díaz J, Acevedo Alcaraz C, Blazquez-Manzanera AL, Padilla Jiménez AML, Baamonde Calzada MC, Vera M, Cháfer Rudilla M, Canalda Campás M, García Muñoz S, Vicente Gutiérrez L, Jiménez Añón L, Pérez Martínez A, Pons Castillo A, González Tamayo R, Férriz Vivancos J, Rodríguez-Fraga O, Díaz F, de Brito FV, Aguadero V, García Arévalo MG, Arnaldos Carrillo M, González Morales M, Núñez Gárate M, Ruiz Iruela C, Sancho-Rodríguez N, Vila Pérez M, Egea-Caparrós JM, Sáenz L, Blasco Barbero Á, Galán Ortega A (2021) Characteristics and laboratory findings on admission to the emergency department among 2873 hospitalized patients with COVID-19: the impact of adjusted laboratory tests in multicenter studies. A multicenter study in Spain (BIOCOVID-Spain study). Scand J Clin Lab Invest 81:187-193. https://doi.org/10.1080/00365513.2021.1881997

20. Meijer P, Kluft C (2005) The harmonization of quantitative test results of different D-dimer methods. Semin Vasc Med 5:321-327. https://doi.org/10.1055/s-2005-922477

21. Meijer P, Haverkate F, Kluft C, de Moerloose P, Verbruggen B, Spannagl M (2006) A model for the harmonisation of test results of different quantitative D-dimer methods. Thromb Haemost 95:567-572. https://doi.org/10.1160/TH05-01-0042

22. Landis JR, Koch GG (1977) The measurement of observer agreement for categorical data. Biometrics 33:159-174

23. Casas-Rojo JM, Antón-Santos JM, Millán-Núñez-Cortés J, Lumbreras-Bermejo C, Ramos-Rincón JM, Roy-Vallejo E, ArteroMora A, Arnalich-Fernández F, García-Bruñén JM, Vargas-Núñez JA, Freire-Castro SJ, Manzano-Espinosa L, Perales-Fraile I, Crestelo-Viéitez A, Puchades-Gimeno F, Rodilla-Sala E, Solís-Marquínez MN, Bonet-Tur D, Fidalgo-Moreno MP, Fonseca-Aizpuru 
EM, Carrasco-Sánchez FJ, Rabadán-Pejenaute E, Rubio-Rivas M, Torres-Pea JD, Gómez-Huelgas R, en nombre del Grupo SEMICOVID-19 Network (2020) Clinical characteristics of patients hospitalized with COVID-19 in Spain: results from the SEMICOVID-19 Registry. Rev Clin Esp 220:480-494. https://doi.org/ 10.1016/j.rce.2020.07.003

24. Berenguer J, Ryan P, Rodríguez-Baño J, Jarrín I, Carratalà J, Pachón J, Yllescas M, Arriba JR, COVID-19@Spain Study Group (2020) Characteristics and predictors of death among 4,035 consecutively hospitalized patients with COVID-19 in Spain. Clin Microbiol Infect 26:1525-1536. https://doi.org/10.1016/j.cmi. 2020.07.024

25. Görlinger K, Dirkmann D, Gandhi A, Simioni P (2020) COVID19-associated coagulopathy and inflammatory response: what do we know already and what are the knowledge gaps? Anesth Analg 131:1324-1333. https://doi.org/10.1213/ANE.0000000000005147

26. Iba T, Levy JH, Connors JM, Warkentin TE, Thachil J, Levi M (2020) The unique characteristics of COVID-19 coagulopathy. Crit Care 24:360. https://doi.org/10.1186/s13054-020-03077-0

27. Franchini M, Marano G, Cruciani M, Mengoli C, Pati I, Masiello F, Veropalumbo E, Pupella S, Vaglio S, Liumbruno GM (2020) COVID-19-associated coagulopathy. Diagnosis (Berl) 7:357-363. https://doi.org/10.1515/dx-2020-0078

28. Thompson S, Bohn MK, Mancini N, Loh TP, Wang CB, Grimmler M, Yuen KY, Mueller R, Koch D, Sethi S, Rawlinson WD, Clementi M, Erasmus R, Leportier M, Kwon GC, Menezes ME, Patru MM, Gramegna M, Singh K, Najjar O, Ferrari M, Lippi G, Adeli K, Horvath AR, IFCC Taskforce on COVID-19 (2020) IFCC interim guidelines on biochemical/hematological monitoring of COVID-19 patients. Clin Chem Lab Med 58:2009-2016. https:// doi.org/10.1515/cclm-2020-1414

29. Iba T, Connors JM, Levy JH (2020) The coagulopathy, endotheliopathy, and vasculitis of COVID-19. Inflamm Res 69:1181-1189. https://doi.org/10.1007/s00011-020-01401-6

30. Gris JC, Loubet P, Roger C, Cochery-Nouvellon E, Mauboussin JM, Muller L, Bouvier S, Laureillard D, Barbar SD, Mercier É, Lefrant JY, Sotto A (2020) The association between D-dimers in COVID-19 patients and mortality remains beset of uncertainties. J Thromb Haemost 18:2068-2070. https://doi.org/10.1111/jth. 14941

31. Berger JS, Kunichoff D, Adhikari S, Ahuja T, Amoroso N, Aphinyanaphongs Y, Cao M, Goldenberg R, Hindenburg A, Horowitz J, Parnia S, Petrilli C, Reynolds H, Simon E, Slater J, Yaghi S, Yuriditsky E, Hochman J, Horwitz LI (2020) Prevalence and outcomes of D-dimer elevation in hospitalized patients with COVID19. Arterioscler Thromb Vasc Biol 40:2539-2547. https://doi.org/ 10.1161/ATVBAHA. 120.314872

32. Thachil J (2020) All those D-dimers in COVID-19. J Thromb Haemost 18:2075-2076. https://doi.org/10.1111/jth.14939

33. Trimaille A, Thachil J, Marchandot B, Curtiaud A, Leonard-Lorant I, Carmona A, Matsushita K, Sato C, Sattler L, Grunebaum L, Hansmann Y, Fafi-Kremer S, Jesel L, Ohana M, Morel O (2020)
D-dimers level as a possible marker of extravascular fibrinolysis in COVID-19 patients. J Clin Med 10:39. https://doi.org/10.3390/ jcm10010039

34. Shetty S, Padijnayayveetil J, Tucker T, Stankowska D, Idell S (2008) The fibrinolytic system and the regulation of lung epithelial cell proteolysis, signaling, and cellular viability. Am J Physiol Lung Cell Mol Physiol 295:967-975. https://doi.org/10.1152/ajplu ng.90349.2008

35. Connors JM, Levy JH (2020) COVID-19 and its implications for thrombosis and anticoagulation. Blood 135:2033-2040. https:// doi.org/10.1182/blood.2020006000

36. Hunt BJ, Levi M (2020) Re the source of elevated plasma D-dimer levels in COVID-19 infection. Br J Haematol 190:e133-e134. https://doi.org/10.1111/bjh.16907

37. Chocron R, Duceau B, Gendron N, Ezzouhairi N, Khider L, TrimailleA GG, Weizman O, Alsac JM, Pommier T, Bory O, Cellier J, Philippe A, Geneste L, Abdallah IB, Panagides V, Batti SE, Marsou W, Juvin P, Deney A, Messas E, Attou S, Planquette B, Mika D, Gaussem P, Fauvel C, Diehl J-L, Pezel T, Mirault T, Sutter W, Sanchez O, Bonnet G, Cohen A, Smadja DM (2021) D-dimers at hospital admission for COVID-19 are associated with in-hospital mortality, independent of venous thromboembolism: Insights from a French multicentre cohort study. Arch Cardiovasc Dis. https://doi.org/10.1016/j.acvd.2021.02.003

38. Zhang L, Yan X, Fan Q, Liu H, Liu X, Liu Z, Zhang Z (2020) D-dimer levels on admission to predict in-hospital mortality in patients with Covid-19. J Thromb Haemost 18:1324-1329. https:// doi.org/10.1111/jth.14859

39. Yao Y, Cao J, Wang Q, Shi Q, Liu K, Luo Z, Chen X, Chen S, Yu K, Huang Z, Hu B (2020) D-dimer as a biomarker for disease severity and mortality in COVID-19 patients: a case control study. J Intensive Care 8:49. https://doi.org/10.1186/ s40560-020-00466-Z

40. Naymagon L, Zubizarreta N, Feld J, van Gerwen M, Alsen M, Thibaud S, Kessler A, Venugopal S, Makki I, Qin Q, Dharmapuri S, Jun T, Bhalla S, Berwick S, Christian K, Mascarenhas J, Dembitzer F, Moshier E, Tremblay D (2020) Admission D-dimer levels, D-dimer trends, and outcomes in COVID-19. Thromb Res 196:99-105. https://doi.org/10.1016/j.thromres.2020.08.032

41. Wagner J, Garcia-Rodriguez V, Yu A, Dutra B, DuPont A, Cash B, Farooq A (2020) Elevated D-dimer is associated with multiple clinical outcomes in hospitalized Covid-19 patients: a retrospective cohort study. SN Compr Clin Med 8:1-7. https://doi.org/10. 1007/s42399-020-00627-z

42. Fu J, Kong J, Wang W, Wu M, Yao L, Wang Z, Jin J, Wu D, Yu X (2020) Yu X (2020) The clinical implication of dynamic neutrophil to lymphocyte ratio and D-dimer in COVID-19: a retrospective study in Suzhou China. Thromb Res 192:3-8. https://doi.org/ 10.1016/j.thromres.2020.05.006

Publisher's Note Springer Nature remains neutral with regard to jurisdictional claims in published maps and institutional affiliations.

\section{Authors and Affiliations}

Luis García de Guadiana-Romualdo ${ }^{1}$ - Daniel Morell-García ${ }^{2}$ - Emmanuel J. Favaloro ${ }^{3}$ Juan A. Vílchez ${ }^{4}$. Josep M. Bauça ${ }^{2}$. María J. Alcaide Martín ${ }^{5}$. Irene Gutiérrez Garcia ${ }^{6}$. Patricia de la Hera Cagigal ${ }^{7}$. José Manuel Egea-Caparrós ${ }^{8}$. Sonia Pérez Sanmartín ${ }^{9}$. José I. Gutiérrez Revilla ${ }^{10}$. Eloísa Urrechaga ${ }^{11}$. Jose M. Álamo ${ }^{12}$. Ana M. Hernando Holgado ${ }^{13}$. María-Carmen Lorenzo-Lozano ${ }^{14}$. Magdalena Canalda Campás ${ }^{15}$. María A. Juncos Tobarra ${ }^{16}$. Cristian Morales-Indiano ${ }^{17}$. Isabel Vírseda Chamorro ${ }^{18}$. Yolanda Pastor Murcia ${ }^{19}$. Laura Sahuquillo Frías ${ }^{20}$. Laura Altimira Queral ${ }^{21}$. Elisa Nuez-Zaragoza ${ }^{22}$. Juan Adell Ruiz de León ${ }^{23}$. Alicia Ruiz Ripa ${ }^{24}$ • Paloma Salas Gómez-Pablos ${ }^{25}$ • Iria Cebreiros López ${ }^{26}$. Amaia Fernández Uriarte ${ }^{27}$. 
Alex Larruzea ${ }^{28} \cdot$ María L. López Yepes ${ }^{29} \cdot$ Natalia Sancho-Rodríguez ${ }^{30} \cdot$ María C. Zamorano Andrés $^{31}$. José Pedregosa Díaz ${ }^{32}$ - Luis Sáenz ${ }^{33}$. Clara Esparza del Valle ${ }^{9}$ María C. Baamonde Calzada ${ }^{10}$. Sara García Muñoz ${ }^{7}$. Marina Vera ${ }^{12}$. Esther Martín Torres ${ }^{14}$. Silvia Sánchez Fdez-Pacheco ${ }^{15}$. Luis Vicente Gutiérrez ${ }^{16}$. Laura Jiménez Añón ${ }^{17}$. Alfonso Pérez Martínez ${ }^{4}$. Aurelio Pons Castillo ${ }^{18}$. Ruth González Tamayo ${ }^{6}$. Jorge Férriz Vivancos ${ }^{19}$. Olaia Rodríguez-Fraga ${ }^{5}$. Vicens Díaz-Brito ${ }^{34}$. Vicente Aguadero ${ }^{22}$ - M. G. García Arévalo ${ }^{23}$. María Arnaldos Carrillo ${ }^{26}$. Mercedes González Morales ${ }^{1}$ - María Núñez Gárate ${ }^{27}$. Cristina Ruiz Iruela ${ }^{28}$. Patricia Esteban Torrella ${ }^{30}$. Martí Vila Pérez ${ }^{32}$. Cristina Acevedo Alcaraz ${ }^{8}$. Alfonso L. Blázquez-Manzanera ${ }^{33}$. Amparo Galán Ortega ${ }^{35}$

1 Laboratory Medicine Department, Hospital Universitario Santa Lucía, C/ Mezquita, s/n, Paraje Los Arcos, Santa Lucía, 30202 Cartagena, Spain

2 Laboratory Medicine Department, Hospital Universitario Son Espases, Palma de Mallorca, Spain

3 Haematology, Sydney Centres for Thrombosis and Haemostasis, Institute of Clinical Pathology and Medical Research (ICPMR), NSW Health Pathology, Westmead Hospital, Westmead, NSW, Australia

4 Laboratory Medicine Department, Hospital Universitario Morales Meseguer, Murcia, Spain

5 Laboratory Medicine Department, Hospital Universitario La Paz, Madrid, Spain

6 Laboratory Medicine Department, Hospital Universitario de Torrevieja, Torrevieja, Spain

7 Laboratory Medicine Department, Hospital Universitario de Basurto, Bilbao, Spain

8 Laboratory Medicine Department, Hospital Universitario Los Arcos del Mar Menor, San Javier, Spain

9 Laboratory Medicine Department, Hospital Universitario Marqués de Valdecilla, Santander, Spain

10 Department of Clinical Biochemistry, Hospital Sierrallana, Torrelavega, Spain

11 Biocruces Bizkaia Health Research Institute, Baracaldo, Spain

12 Biochemical Laboratory, Hospital Marina Baixa, Villajoyosa, Spain

13 Laboratory Medicine Department, Hospital Universitario Vinalopó, Elche, Spain

14 Laboratory Medicine Department, Complejo Hospitalario de Toledo, Toledo, Spain

15 Laboratory Medicine Department, Hospital Central de La Defensa Gómez Ulla, Madrid, Spain

16 Laboratory Medicine Department, Complejo Hospitalario Universitario de Albacete, Albacete, Spain

17 Laboratory Medicine Department, Hospital Universitari Germans Trias I Pujol, Badalona, Barcelona, Spain
18 Laboratory Medicine Department, Hospital Arnau de Vilanova, Valencia, Spain

19 Laboratory Medicine Department, Consorci Hospital General Universitari de València, Valencia, Spain

20 Laboratory Medicine Department, Hospital Can Misses, Ibiza, Spain

21 Laboratory Medicine Department, Parc Sanitari Sant Joan de Déu, Sant Boi de Llobregat, Spain

22 Clinical Laboratory Department, Hospital Universitari Parc Taulí, Sabadell, Spain

23 Laboratory Medicine Department, Hospital Universitario Virgen de La Victoria, Málaga, Spain

24 Laboratory Medicine Department, Laboratori de Referència de Catalunya. Hospital de Mataró, Mataró, Spain

25 Catlab, Consorci Sanitari de Terrassa, Terrassa, Spain

26 Laboratory Medicine Department, Hospital Universitario Virgen de La Arrixaca, Murcia, Spain

27 Catlab, Hospital Universitario Mútua Terrassa, Barcelona, Spain

28 Laboratory Medicine Department, Hospital Fundació Sanitària Hospital de Mollet, Barcelona, Spain

29 Laboratory Medicine Department, Hospital Virgen del Castillo, Yecla, Spain

30 Laboratory Medicine Department, Hospital General Universitario Reina Sofía, Murcia, Spain

31 Laboratory Medicine Department, Hospital de La Vega Lorenzo Guirao, Cieza, Spain

32 Laboratory Medicine Department, Hospital Verge de La Cinta, Tortosa, Spain

33 Laboratory Medicine Department, Hospital General Universitario Rafael Méndez, Lorca, Spain

34 Internal Medicine Department, Parc Sanitari Sant Joan de Déu,, Sant Boi de Llobregat, Spain

35 Comisión de Magnitudes Biológicas Relacionadas Con La Urgencia Médica, Sociedad Española de Medicina de Laboratorio (SEQC-ML), Barcelona, Spain 